\title{
SISTEMAS DE INFORMAÇÃO: PAPEL E APLICAÇÕES NO SEGMENTO INDUSTRIAL
}

Alceri Antonio Schlotefeldt ${ }^{1}$

RESUMO

À medida que os processos empresariais do segmento produtivo industrial tornaramse mais complexos, ampliou-se a necessidade de maior controle destas atividades e melhor tempo de resposta às demandas por informações apresentadas. Estas demandas foram motivadas em função da globalização e de uma maior concorrência interna no segmento. Este artigo pretende contribuir com a discussão sobre informação e sistemas de informação no segmento industrial, abordar suas características e aplicação, além de apresentar algumas vantagens de sua utilização e sua aplicação no ambiente empresarial deste segmento, bem como, discute-se a governança de TI no contexto das organizações. Para tanto, será utilizada a metodologia descritiva baseada em diferentes autores sobre o tema sistema de informação e sua implicação nas empresas e organizações.

Palavras-chave: Informação. Sistemas de Informação. Integração. Governança.

${ }^{1}$ Especialista, e-mail: alceri@sc.senai.br 


\section{INTRODUÇÃO}

Com o passar do tempo, as empresas e organizações foram percebendo as necessidades inerentes ao controle de suas atividades e processos. Estas necessidades foram evidenciadas mais fortemente à medida que as operações e seus processos tornaramse mais completos e, por conseguinte, mais complexos. Além disso, o volume de dados e informações que passaram a transitar nas empresas foi elevado sobremaneira. Neste contexto, as ferramentas e meios de controle, passaram a fazer parte do universo de discussão nas organizações e surge com força o termo sistemas de informação, como uma possível resposta a estas demandas.

Nesta crescência de necessidades, as empresas de manufatura e de transformação tem pesadamente investido em tecnologia da informação e sistemas de informação com a perspectiva de atingir tais objetivos.

Os sistemas de informação, para O’Brien, (2004), são um conjunto organizado de pessoas, hardware, software, redes de comunicação e recursos de dados que coletam transformam e disseminam informações em uma organização.

Neste artigo, busca-se apresentar alguns dos principais conceitos sobre informações e sistemas de informação, suas generalidades e conceitos, além de sua aplicação no universo das empresas e organizações e o impacto da governança de TI no contexto das organizações. A julgar pela relevância do tema, a importância deste trabalho dáse pela possibilidade de compreender melhor o conceito, aplicações e vantagens deste conceito pelas empresas na busca de maior agilidade na tomada de decisão e controle de seus processos. A construção e organização básica deste artigo estrutura-se em três partes, sendo que a primeira parte versa sobre o conceito de informação, a segunda parte aborda o conceito e caracterização dos sistemas de informação e a terceira parte apresenta a aplicação dos sistemas de informação no segmento industrial. Ao final do artigo, espera-se que o leitor compreenda a definição, aplicação e características dos sistemas de informação e sua aplicação no segmento industrial.

\section{INFORMAÇÃO}

De acordo com o dicionário Aurélio, informação significa "ato ou efeito de informar-se, ou fatos conhecidos ou dados acerca de alguém ou alguma coisa". No contexto atual das organizações, a palavra informação passou a ser a "chave" de uma série de questões que envolvem, entre outras, a tomada de decisão baseada em informação e conhecimento. Assim, ao buscar uma definição apropriada para a palavra "informação", percebe-se grande variedade de significados. Para Caiçara, (2008) a informação pode ser entendida como a medida da incerteza sobre um determinado estado de coisas por intermédio de uma mensagem. Torna-se necessário compreender que um dado transforma-se em informação à proporção que adquire contexto, ou seja, a informação é um dado contextualizado. Um dado é um fato bruto, sem contexto e por si só, pouco relevante. Já informação vem do latim informare, que significa "dar forma". 
Uma empresa gera milhares de dados sobre seu funcionamento, como dados da produção, de vendas, de recebimento, de pagamento, entre tantos outros. Entende-se como dados, neste contexto, o conjunto de elementos que expressa um fato isolado gerado por uma atividade que pode ser controlada, ou seja, tudo que é gerado no dia-adia da empresa é dado. (BATISTA, 2006). Entretanto, uma grande quantidade de dados existentes não teria qualquer importância, se não pudesse ser organizada e classificada conforme a necessidade. Estes dados organizados e classificados para suprir um objetivo específico, são chamados de informação.

Pode-se então concluir, que a informação utiliza como matéria-prima, os dados. Desta forma, compreende-se que informação são dados moldados de uma forma significativa e útil para as pessoas.

Neste cenário, considera-se a informação, o maior ativo ou diferencial competitivo da empresa. Normalmente, a partir desta concepção, as empresas passam a valorizar mais as informações, recurso normalmente intangível e de difícil mensuração. Quanto maior o volume e a qualidade da informação, disponibilizada de forma correta e em tempo hábil, melhor será o desempenho na tomada de decisões e melhor o controle sobre os processos que dependem destas informações. No entanto, com o aumento significativo do volume e da complexidade das informações necessárias às organizações, torna-se necessário o uso de ferramentas computacionais que permitam maior velocidade e maior disponibilidade das informações às pessoas interessadas. Assim, os sistemas de informação permitem respostas às demandas apresentadas, com velocidade, segurança e qualidade necessária a execução dos processos.

\subsection{SISTEMAS DE INFORMAÇÃO}

Considera-se um sistema, um conjunto de elementos interdependentes em um todo organizado, ou partes que interagem formando um todo unitário e complexo. Entretanto, é necessário compreender que os sistemas podem ser abertos ou fechados, sendo que o primeiro, está em constante interação com o meio, influenciando e sendo influenciado. Já o segundo (sistema fechado), apesar de estar inserido em um meio, não sofre alteração e também não causa interação no meio onde está inserido. Um sistema de informação, naturalmente, é considerado um sistema aberto, visto que faz interface com o meio ambiente (macro), sofre interferência deste meio e influencia o meio onde está inserido.

Os sistemas de informação têm assumido importante papel no mundo corporativo. Uma de suas principais vantagens é o controle que torna-se possível a partir de sua utilização. Outra vantagem na sua utilização é a rapidez de resposta para a tomada de decisão. Para Loudon e Loudon (1996 apud ROSINI, 2003) sistemas de informação são componentes relacionados entre si, atuando em conjunto para coletar, processar e prover informações aos sistemas e/ou aos processos de decisão, coordenando, controlando, visualizando e analisando processos internos a organização. 
Para obter um bom desempenho em suas funções, um sistema de informação deve estar integrado com a organização, coletando dados e transformando em informações úteis para o processo decisório. Desta forma, um sistema de informação configurase como um processamento de recursos (entrada do sistema) e obtém-se com este processamento (processo) as saídas do produto da informação. A figura 1 apresenta de forma esquemática este contexto.

Figura 1: Estrutura esquemática de ecossistema e sistema

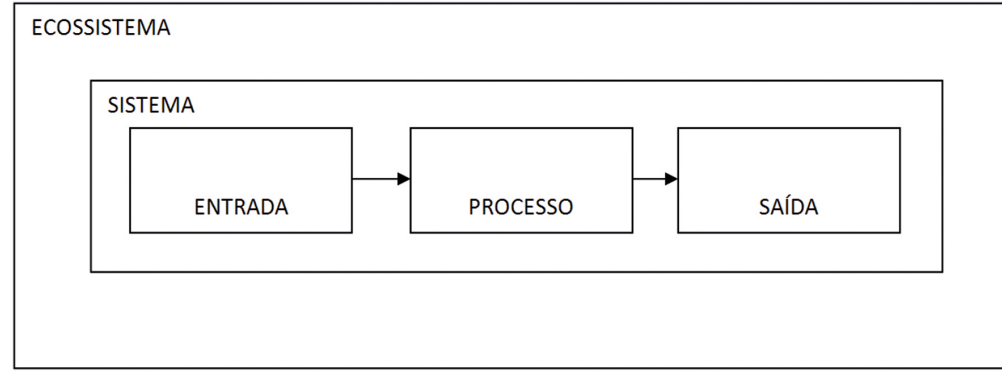

Fonte: Adaptado de Marques (2006)

As pessoas e organizações têm recorrido aos sistemas de informação para se comunicarem, utilizando uma diversidade cada vez maior de hardware (equipamentos físicos), instruções e procedimentos (softwares), canais de comunicação (redes) e dados armazenados (recursos de dados). A figura 2 apresenta os recursos de um sistema de informação.

Figura 2: Recursos de um sistema de informação

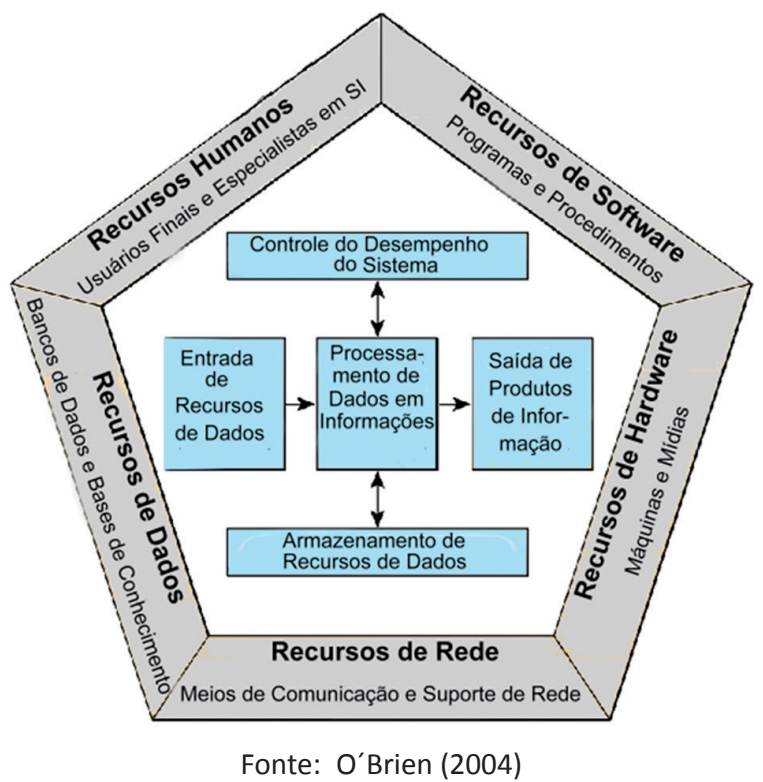

De Sordi (2010), detalha os recursos de um sistema de informação, apresentando as principais características de cada um dos recursos, quais sejam: 
a) recursos humanos: profissionais da área de informática e de outras áreas técnicas, como telecomunicações, responsáveis por construir, operar e aprimorar o sistema de informação. Além dos técnicos, deve-se ressaltar a comunidade de clientes do sistema, seus usuários finais;

b) recurso de software: abrangem todos os softwares necessários para o processamento dos algoritmos que constituem o sistema de informação;

c) recurso de hardware: também chamado de recursos de tecnologia da informação, este recurso é composto de processadores (CPU), meios de armazenamento (fitotecas, unidades de disco), equipamentos para a interação homem-máquina (teclado, mouse, monitores, impressoras), entre outros dispositivos físicos que constituem o que, convencionalmente, se denomina computador;

d) recurso de rede: equipamentos e softwares específicos para a operação e gestão do tráfego de dados e informações entre computadores. Abrangem desde softwares para gerenciamento de redes até equipamentos, como switches e roteadores;

e) recurso de dados: é o conjunto de caracteres armazenados, que constituise como dados ou informação, bem como o conjunto de atributos a eles referentes: tamanho, localização, seus usuários, período de atualização, data da criação e outros.

Um sistema de informação, na concepção de Bio (2008), é um subsistema do "sistema empresa" e dentro da mesma linha de raciocínio pode-se concluir que seja composto de um conjunto de subsistemas de informação, por definição, interdependentes. Assim, é possível pensar em subsistemas de orçamento, custos, contabilidade e outros, como componentes do sistema de informação maior (ou total) da empresa. Apesar do conceito de sistemas de informação não se referir a este ou aquele meio de processamento, em termos práticos o computador é o que torna possível cogitar um grau maior de integração e posterior controle por parte das empresas.

Para De Sordi (2010), os sistemas de informação integrados podem ser considerados um tipo particular de sistemas de informação e a integração é sua principal característica. Esta integração é um agregado importante para as funções e papeis desempenhados pelos sistemas de informação para efeitos de controle e maior disponibilidade da informação para as pessoas que se utilizam dos sistemas. Percebe-se, portanto, que o processo decisório passou a verificar que informações antes consideradas irrelevantes, agora passam (ou podem passar a ser) cruciais para a tomada de decisão de uma empresa. 


\subsection{A informação, os sistemas de informação no segmento industrial e a governança de $\mathrm{TI}$}

O desafio exposto ao segmento produtivo industrial se mostra cada vez maior e mais relevante à medida que as empresas deste segmento enfrentam maior concorrência e necessitam diminuir seu tempo de resposta. Quanto mais efetiva for a concorrência, melhor deverá ser o desempenho da indústria para manter-se no mercado onde atua. Para Morgan e Liker (2008), empresas de todo mundo tentam encontrar meios de agilizar o desenvolvimento de produtos, vendo nisso a melhor maneira de estabelecer vantagem competitiva. Uma das formas de alcançar esta vantagem é uso constante e acelerado de tecnologia e ferramentas computacionais. Entretanto, o sucesso na utilização destas ferramentas e tecnologias, depende da capacidade de customizá-las em função da empresa de forma a torná-las exclusivas e integrá-las completamente aos processos produtivos.

Para Martins (2008) uma área amplamente atendida pelos sistemas de informação é o Planejamento e Programação da Produção (PCP), responsável por planejar, programar e controlar as operações de manufatura, de forma a alimentar os clientes com informações atualizadas sobre as entregas dos produtos e permitir a programação dos fornecedores de matérias-primas.

Para Batista (2006), o objetivo de utilizar sistemas de informação em uma organização é a criação de um ambiente empresarial em que as informações sejam confiaveis e possam fluir na estrutura organizacional. No entanto, é necessario que uma organização conheça as suas necessidades de informações operacionais e gerenciais para que, assim, mediante a implantação de um sistema de informação adequado, possa começar atender estas necessidades. Atualmente, um agravante na seleção, implantação e utilização de sistemas de informação pelas empresas do segmento produtivo tem sido, exatamente, a dificuldade de saber extratificar de forma coerente quais são as informações que são necessárias para o desempenho eficaz e eficiente das organizações. Muitas são as opções de pacotes de sistemas prontos, mas nem sempre a acertada escolha é algo simples para as indústrias.

O contexto empresarial produtivo e os demais processos constantes no mundo globalizado, tornam-se cada vez mais interdependentes do ponto de vista informacional, ou seja, as informações perpassam todas as áreas e acompanham os produtos e processos. De Sordi (2010) destaca que o ambiente de negócios é altamente colaborativo e torna-se cada vez mais comum falar sobre cadeias colaborativas, cadeias de valor, arranjos produtivos locais, cadeia de fornecedores e demais práticas do ambiente administrativo que remetem ao trabalho conjunto e a necessidade de conexão entre os diferentes setores, segmentos atores do processo produtivo. Em Paim et al. (2009), encontra-se que as ferramentas computacionas, ou sistemas de informação, tem função de análise e de representação que concretizam a verificação, a avaliação e a modificação dos processos e das estruturas organizacionais. A figura 3 apresenta a idéia de processos e sistemas dentro de uma dada organização que podem ser integrados ao longo de uma 
cadeia de suprimentos (no segmento industrial, por exemplo). A mesma figura destaca que integrar processos entre empresas significa integrar sistemas de informação das empresas que são os elos de uma dada cadeia de suprimentos.

É importante ressaltar que a integração proposta na figura, precisa manter características essenciais de ambos os processos ou ambas empresas e ao mesmo tempo absorver uma outra caracteristica (hibrida) que vem, exatamente, da junção e da integração dos processos ou empresa.

Figura 3: Interface do processo entre organizações

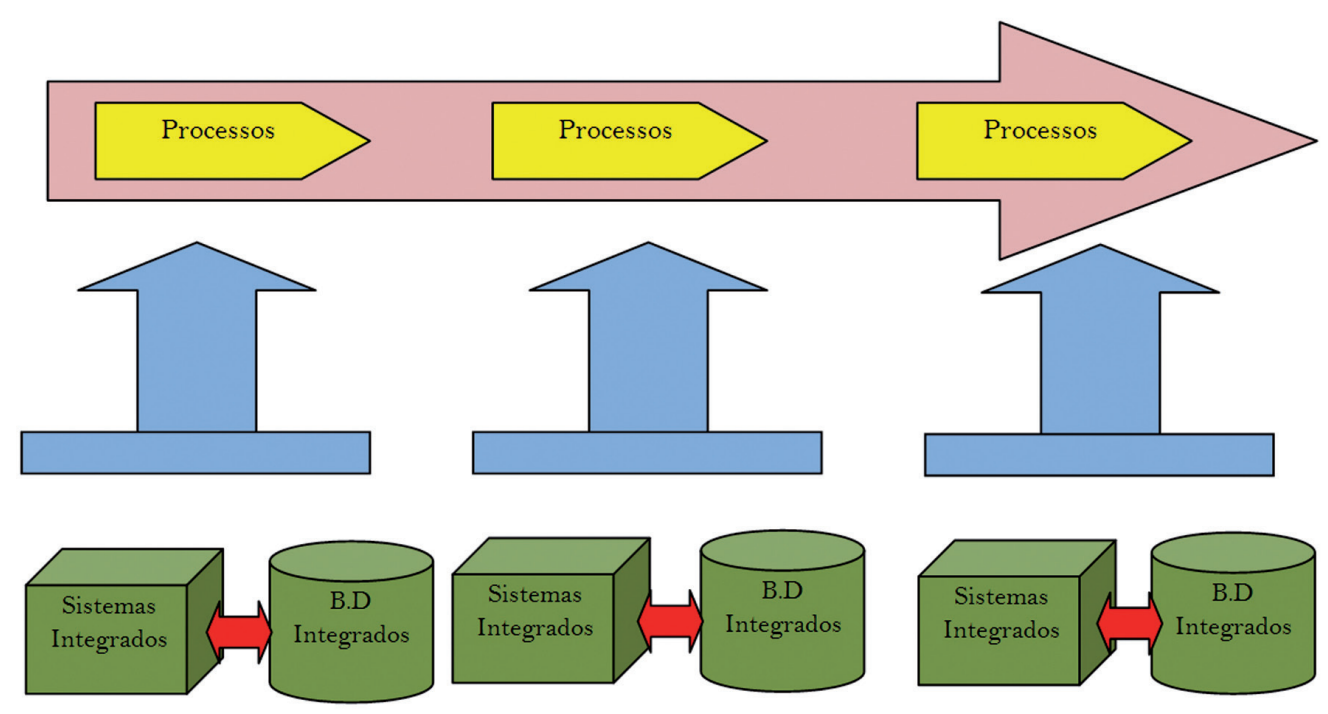

Fonte: Paim, et al.(2009)

Codeceira (2009) esclarece a importância da circulação deste ativo importante da indústria - que é a informação e a necessidade da efetiva gerência - que atualmente é tratada como governança de TI - sobre este ativo. A Governança de TI consiste em estrutura organizacional, processos e lideranças para garantir que:
a) a TI sustente e auxilie as estratégias e os objetivos da organização;
b) garanta controles;
c) amplie processos de segurança e processos produtivos;
d) minimize os riscos;
e) amplie o desempenho;
f) aperfeiçoe as aplicações de recursos; 
g) reduza os custos;

h) suporte as decisões e;

i) alinhe a TI aos negócios.

Desta forma, o que se espera é que no segmento industrial esta realidade possa cada vez mais aproximar processos e viabilizar melhorias no tempo de resposta exigido pelo mercado das indústrias produtoras.

A figura 4 mostra como a governança de Tl interage com todos os segmentos dentro da indústria e promove a circulação da informação dentre os diferentes processos e setores.

Figura 4: Esquema básico de governança de TI

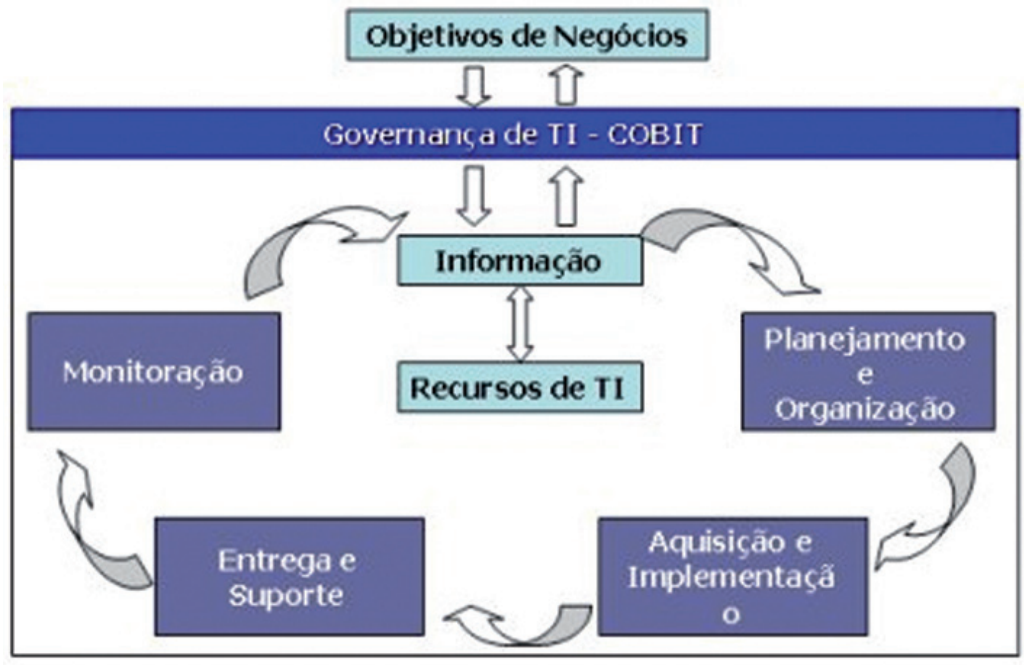

Fonte: Codeceira (2009)

Para Bio (2008), a essência do planejamento e do controle é a tomada de decisão. Essa por sua vez, depende de informações oportunas, de conteúdo adequado e confiável. Isto pressupõe certo grau de consciência por parte dos executivos sobre os processos decisórios em que estão envolvidos e o desenvolvimento de um sistema de informação sintonizado com as necessidades de informação deste processo decisório. O mesmo autor admite ainda, que as informações internas também refletem premissas básicas para o planejamento, tais como capacidade de produção, custos, rentabilidade por produto, informações históricas sobre evolução de vendas, e outras informações internas pertinentes ao negócio.

As informações para a identificação de restrições internas, quando cotejadas às informações externas, são premissas vitais para a tomada de decisão por ocasião do planejamento. 
Do ponto de vista da informação para o controle, esta envolve:

a) informações mercadológicas, ou seja, aquelas referentes a execução real dos planos mercadológicos e de vendas;

b) informação de produção, ou seja, quantidades, prazos, custos para acompanhamento dos planos e orçamentos de produção;

c) informação econômico-financeiras, ou seja, ampla gama de informações sobre custos, rentabilidade, situação financeira, fluxo de caixa e demais informações pertinentes.

A partir deste entendimento, fica evidente que a chave do êxito do ciclo "planejamentodireção-ação-resultado-controle" repousa num sistema de informação adequado às necessidades dos processos decisórios. (BIO, 2008).

Por ser considerado um sistema aberto (de acordo com definição anterior), Batista, 2006, afirma que uma característica peculiar dos sistemas de informação gerencial é a necessidade de estar sempre mudando para atender ao dinamismo do mundo dos negócios, exatamente o que qualquer organização precisa para sobreviver no mercado. Este entendimento é peça chave no sucesso da implantação e utilização dos sistemas de informação pelas empresas. Algumas empresas ainda acreditam (equivocadamente) que o simples fato de possuir a maior quantidade de computadores possíveis é suficiente para ter um sistema de informação automatizado e que possa satisfazer sua necessidade. Entretanto, o conceito e o "DNA" da empresa pelo uso de sistema de informação é que permitirá alcançar a eficiência e eficácia em seus processos, utilizando-se de informações relevantes advindas de um sistema de informação.

De forma geral, as tecnologias de informação em que as empresas mais confiaram e investiram nos últimos anos, objetivando promover reengenharia e gestão por processos, foram os sistemas de gestão empresarial integrada (ERP) e a base de dados corporativa. (DE SORDI, 2010).

A grande vantagem, que De Sordi (2010) apresenta para o uso dos ERP's no meio empresarial, é a importante integração de um grande número de transações de negócios através de uma base de dados central, implementada por meio de um sistema gerenciador de banco de dados, que permite o compartilhamento e o armazenamento centralizado das informações de interesse comum da empresas e de seus processos.

De forma mais ampla, pode-se afirmar que os sistemas de informação são um conjunto de softwares, conhecimento e procedimentos que suportam a execução de diversas transações de negócio e a manipulação de dados altamente relacionados". (DE SORDI, 2010).

Para Siqueira (2005), isto mostra que as organizações, nesta nova realidade, necessitarão de processos de tomada de decisão cada vez mais frequentes e mais rápidos, constante 
inovação organizacional, formas contidas e estruturadas de aquisição de informação e modelos de captação e distribuição da informação. O mesmo autor afirma que as empresas precisam de qualidade, valor agregado, inovação, flexibilidade, agilidade e velocidade de formas cada vez a mais críticas. As empresas do segmento fabril, tendem a se diferenciar pelo que elas sabem e pela forma que conseguem usar suas informações. Isto é possivel com a habilidade de transformar a imensa massa de dados operacionais em informações consistentes que agregem valor ao negócios. Neste contexto, é imprescindivel o uso de um sistema de informação que permita tais aplicações e interface.

Um conjunto de programas especialmente relevante para o sistema de informação é o ERP (Enterprise Resourse Planning) que, usualmente, se divide em módulos que se comunicam e atualizam uma única base de dados central. As informações alimentadas em um módulo são instantaneamente disponibilizadas para os demais que delas dependem. Assim, evita-se redundância de dados e minimiza-se a chance de erros nas informações. Os sistemas integrados são capazes de (teoricamente) integrar toda a empresa dentro de um único sistema de informação com níveis hierárquicos de acesso ao sistema.

Para O'Brien (2004) os níveis hierárquicos de uma organização estão diretamente relacionados com o nível de tomada de decisão gerencial e que se subdivide em 3 grandes áreas:

a) SIG - Sistema de Informação Gerencial que formam o tipo original de sistemas de apoio gerencial e ainda constituem-se como uma categoria importante dos sistemas de informação;

b) SAD - Sistemas de Apoio a Decisão que são os sistemas de informação computadorizados que fornecem apoio interativo de informação aos gerentes e profissionais de empresas durante o processo de tomada de decisão;

c) EIS - Informação Executiva que são sistemas de informação que combinam muitas características dos sistemas de informação gerencial e dos sistemas de apoio a tomada de decisão. Em um EIS, a informação é apresentada de acordo com as preferências dos executivos usuários do sistema. 
A figura 5 apresenta a típica estrutura de decisão e os sistemas característicos em cada nível hierárquico apresentado.

Figura 5: Níveis e classificação dos sistemas de informação

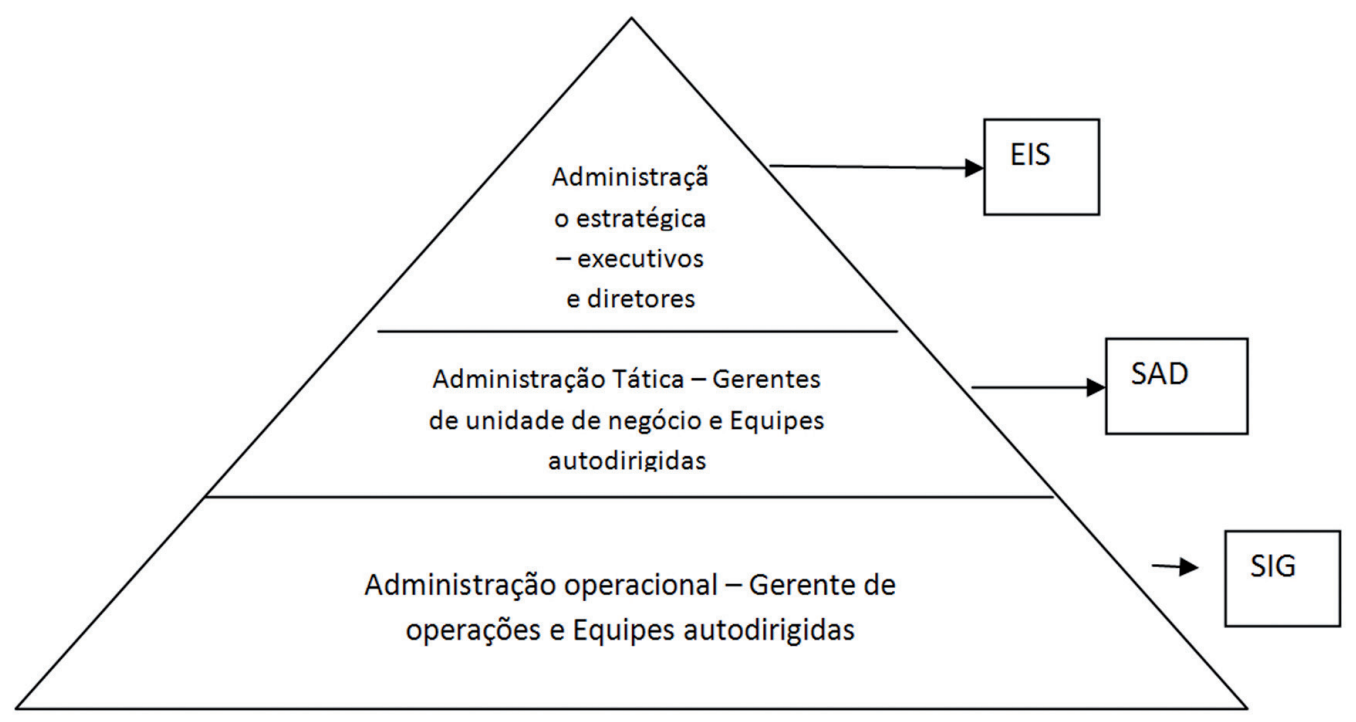

Fonte: Adaptado de O’Brien (2004)

Assim, os sistemas de informação cumprem seu papel fundamental no auxilio aos tomadores de decisão (em todos os níveis), permitindo acesso rápido e disponibilidade da informação no tempo e no formato desejado.

Os sistemas de informação desempenham fundamental papel no processo de tomada de decisão em um ambiente organizacional industrial, pois é nele que os administradores encontram embasamento prático e real em relação às informações que permeiam seus ambientes externos e internos. Desta forma, os administradores e tomadores de decisão, trabalham não tanto por seus sentimentos profissionais, mas com informações idôneas e reais de fatos e acontecimentos, o que permite maior assertividade em suas decisões e ações.

\section{CONSIDERAÇÕES FINAIS}

O crescimento da demanda pela informação, o aumento da quantidade de dados gerados pelas organizações industriais e a maior necessidade de disponibilidade e controle destas informações para tomadas de decisão, levam a empresa a necessitar cada vez mais de sistemas de informação.

O papel dos sistemas de informação vem se tornando evidente na redefinição das forças competitivas nas empresas e ampliando-se ao longo dos anos. Muitas empresas já vêm 
adotando essa nova abordagem, com o objetivo de alcançar sucesso em fatores críticos de competitividade, na qual ela concorre, sejam eles, custo, qualidade, velocidade, confiabilidade ou flexibilidade. (MARTINS, 2008)

Este artigo apresentou os conceitos principais sobre informação, sistemas de informações e governança de $\mathrm{Tl}$, além de apresentar as principais características, aplicações e vantagens do uso dos sistemas de informação no ambiente das organizações industriais, especialmente o do segmento produtivo industrial.

Percebeu-se ao longo do texto que os sistemas de informação tornaram-se peças fundamentais para o desempenho das organizações, não apenas as indústrias, mas de todas as empresas que desejam manter controle de seus negócios e agilidade nos seus processos. Esta afirmativa torna-se evidente quando se observa a necessidade de respostas mais rápidas e decisões muito mais assertivas por parte das organizações industriais. Os sistemas de informação adquiriram um papel preponderante nas atividades industriais, sobretudo àquelas relacionadas ao planejamento, programação e controle da produção, pois estas são áreas onde o desempenho precisa ser constantemente melhorado e tornou-se um terreno fértil para a aplicação de sistemas e tecnologia da informação.

Observa-se o atendimento aos objetivos propostos inicialmente, ao compreender os conceitos principiais dos sistemas de informação e sua interface com o ambiente da organização e sua importância e vantagens de sua aplicação nas organizações, sobretudo nas indústrias. A partir da leitura e o estudo aprofundado de autores que apresentam robusto conhecimento e vivência neste tema, é possível compreender melhor estes conceitos e suas interfaces com o controle e a disponibilidade das informações, premissas fundamentais nos sistemas de informação.

Espera-se que este estudo tenha sido relevante na apresentação destes conceitos, aplicações e vantagens dos sistemas de informação para a contemporaneidade bem como para trabalhos futuros. 


\title{
INFORMATION SYSTEMS: ROLE AND APPLICATIONS IN THE INDUSTRIAL SEGMENT
}

\begin{abstract}
As the business processes of the industrial production segment became more complex, the need for greater control of these activities and better response time to the demands for presented information increased. These demands were motivated by the globalization and increased competition in the domestic segment. This paper contributes to the discussion about information and information systems in the industrial segment, addresses their characteristics and application, and presents some advantages of its use and its application in the business environment in this segment, as well as discusses IT governance in the context of organizations. Thus, we used descriptive methodology based on different authors on the topic of information system and its implication in companies and organizations.
\end{abstract}

Keywords: Information. Information Systems. Integration. Governance.

\section{REFERÊNCIAS}

BATISTA, Emerson de Oliveira. Sistemas de Informação: o uso consciente da tecnologia para o gerenciamento. São Paulo: Saraiva, 2006.

BIO, Sérgio Rodrigues. Sistemas de Informação: um enfoque gerencial. São Paulo: Atlas, 2008.

CAIÇARA Junior, Cícero. Sistemas integrados de gestão - ERP: uma abordagem gerencial. Curitiba: Ibpex, 2008.

CODECEIRA, Viviane. Governança de TI. Blog. [S.I.], 20 out. 2009. Disponível em: <http:// codeceira.wordpress.com/>. Acesso em: 14 jul. 2012.

DE SORDI, José Osvaldo. Administração de sistemas de informação: uma abordagem interativa. São Paulo: Saraiva, 2010.

MARQUES, Wagner Luiz. Sistemas de informação gerencial. Curitiba: SE, 2006.

MARTINS, C. F. O papel da tecnologia da informação na condução do planejamento e controle da produção: um estudo de caso. GEPROS- Gestão da Produção, Operações e Sistemas, Florianópolis, ano 3, n.1, p. 77-89, jan./mar. 2008.

MORGAN, James M.; LIKER, Jeffrey K.. Sistema Toyota de desenvolvimento de produto: Integrando pessoas, processos e tecnologia. Porto Alegre: Bookmann, 2008. 
O'BRIEN, James A. Sistemas de informação e as decisões gerenciais na era da internet. São Paulo: Saraiva, 2004.

PAIM, Rafael et al. Gestão de processos: pensar, agir e aprender. Porto Alegre: Bookman, 2009.

ROSINI, Alessandro Marco. Administração de sistemas de informação e a gestão do conhecimento. São Paulo: Thompson, 2003.

SIQUEIRA, Marcelo Costa. Gestão estratégica da informação. Rio de janeiro: Brasport, 2005.

\section{SOBRE O AUTOR}

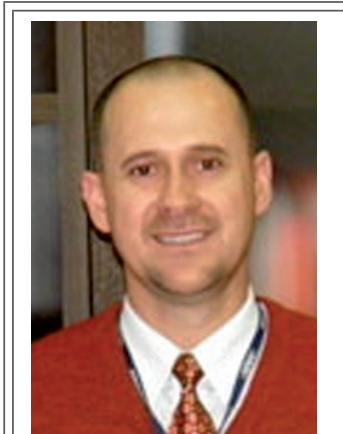

Alceri Antonio Schlotefeldt
Graduado em Sistemas de Informação pela UTESC (União de Tecnologia e escolas de Santa Catarina), Pós Graduado em novas tecnologias aplicadas à educação e MBA em consultoria empresarial, atualmente é mestrando em Engenharia de Produção. Atuou como docente nas áreas de fabricação mecânica, materiais e ensaios mecânicos, além de CAD/CAM e CNC. No SENAI SC em Joinville, foi coordenador do curso técnico em usinagem, coordenador do curso superior de tecnologia em processos industriais e, atualmente é coordenador dos programas de aprendizagem industrial. É docente dos cursos de bacharelado em administração na FCJ - Faculdade Cenecista de Joinville. É Membro efetivo da comissão organizadora do encontro nacional de ferramentas, moldes e matrizes, na ABM em São Paulo. 